Historia

\title{
Historia del Servicio de Ginecología del Instituto Nacional de Cancerología
}

\author{
Gilberto Martínez Morales*
}

El Congreso Nacional aprobó mediante la ley 81 de 1928 la fundación del Instituto Nacional de Radium, como se denominó hasta 1953 cuando se cambió su nombre por el actual, pero por la situación económica imperante en el país y los conflictos con el Perú, solo hasta 1933 pudieron destinarse los fondos necesarios gracias a la cancelación de la amenaza de guerra con el vecino país y el 20 de julio de 1934 fue inaugurado por el presidente Enrique Olaya Herrera.

La historia del Servicio de Ginecología del INC se remonta a los años de la fundación del Instituto si se tiene en cuenta la alta frecuencia con que se presentaba el carcinoma del cuello uterino, patología que junto con los demás tumores que para la época se consideraban susceptibles de tratamiento con radioterapia justificaron la visita del Profesor Regaud en 1928, la ulterior creación del Instituto y la importancia de Francia de la Cúpula de Radium de 2 grs. considerada por esos años lo más avanzado en tecnología. La radioterapia se había consolidado como tratamiento del carcinoma cervical en 1913 en el Congreso de Halle.

En el primer año de labores del Instituto se habían tratado con radioterapia 29 epiteliomas uterinos y se habían declarado intratables a otros cuarenta casos, circunstancia que reflejaba además el estado tan avanzado en que llegaban estas pacientes.

El doctor José Vicente Huertas, cirujano general y primer director de la Institución realizó el 10 de septiembre de 1935 la primera histerectomía abdominal total a una paciente que había sido tratada inicialmente con radioterapia por un epitelioma del cuello uterino, con una duración de 40 minutos y una estancia hospitalaria de 15 días al cabo de los cuales la paciente fue dada de alta en buenas condiciones. El doctor Daniel Brigard quien había recibido entrenamiento en Radioterapia en París colaboraba en el área clínica y en la actualización a los colegas en patología maligna ginecológica. El doctor Luis Urdaneta, entrenado en ginecología en el país, fue el encargado de organizar a comienzos de los años cuarenta el Servicio de Ginecología y se convirtió en su primer jefe; por esos días le colaboraba en algunos procedimientos el doctor Humberto Correa, jefe de Ginecología del Hospital de La Samaritana, quien también se había especializado en París.

El doctor Guillermo López Escobar, egresado de la Universidad Nacional y quien realizó un Máster en

* Jefe del Servicio de Ginecología del Instituto Nacional de Cancerología
Ginecología y Obstetricia en San Luis, Missouri, se vinculó al Instituto en 1948, asumió la jefatura del servicio, implantó las técnicas modernas de cirugía radical vigentes en esa época y el 4 de agosto de 1949 practicó la primera histerolinfadenectomía radical con la técnica de Wertheim-Taussin, muy similar a la preconizada por Meigs del Massachusetts General Hospital en 1940, procedimiento que con ligeras variantes sigue utilizándose universalmente; John Clark, ginecólogo residente en Jonh Hopkins Hospital en 1985 había realizado la primera histerectomía radical con disección de ganglios pélvicos y pocos años más tarde Wertheim en Viena empezó a realizar la histerectomía radical con linfadenectomía pélvica selectiva y la popularizó en Europa y USA. El profesor López también practicó en 1949 la primera vulvectomía radical tipo Basset, quien había propuesto el procedimiento en París en 1911 con algunas diferencias. El doctor López viajó a entrenarse nuevamente en Europa entre 1953 y 1954, realizó estudios en París y en Berlín y en esta última ciudad se entrenó en Colposcopia y a su regreso al país trajo la técnica y un Colposcopio, aparato que aún funciona y que dejó al Instituto por unos pocos pesos cuando en 1966 se fue a California en búsqueda de nuevos conocimientos. El procedimiento ideado en 1925 por Hans Hinselmann, director de la Clínica Ginecológica de la Universidad de Hamburgo permitió entrenar a muchos colegas e implementar en el Instituto el diagnóstico en fase preinvasiva y en estados invasivos tempranos, unos años antes de ser aceptada en Norteamérica, donde el colega colombiano Carlos Vence, fue pionero en la materia al presentarle la técnica que había aprendido en Alemania al profesor Scott.

En París el profesor López tuvo la oportunidad de conocer al doctor Brunschwig quien en 1948 en Nueva York propuso la exenteración para el cáncer cervical avanzado y recurrente y en 1955 inició algunos procedimientos en el Instituto pero con poco entusiasmo dadas las condiciones de la época. Actualmente la exenteración es un procedimiento bastante aceptado en pacientes bien seleccionados y con resultados satisfactorios como quiera que se reportan sobrevidas a 5 años entre el 30 y el $58 \%$ en diferentes series, desde luego las circunstancias tecnológicas y los progresos médicos son distintos.

El doctor Hernán Mendoza, endocrinólogo, en el No. 3 del Boletín del Instituto Nacional de Radium publicado en octubre de 1948 ya hacía referencia a la importancia de la Citología cervicovaginal recordando como el patólogo Georges Papanicolaou en 1928 había descrito la 
presencia de células malignas en la secreción vaginal procedente de un cáncer uterino, pero solo hasta 1943 tomó importancia su contribución. Hacia 1950 el profesor César Mendoza inició algunos procedimientos aislados. El doctor Ricardo Alvarado trabajó durante 2 cortos años como citopatólogo del Instituto a partir de 1958 y la técnica fue impulsada de manera definitiva a partir de 1962 cuando el doctor Armando Santamaría regresó de especializarse en Patología y Citología en Kansas y en la Universidad de Pittsburg y en 1967 logró la fundación de la Escuela de Citología, donde se han capacitado la mayoría de las citotecnólogas que laboran en el país.

El doctor Germán Jordán Abondano ingresó al Instituto en 1954 y fue jefe encargado de Ginecología durante las ausencias del doctor López, había realizado cursos de actualización en oncología ginecológica en USA y desde 1968 asumió la jefatura en propiedad. El doctor Jordán había presentado el trabajo "Carcinoma Intraepitelial del Cuello Uterino" en la Primera Convención Nacional de Obstetricia y Ginecología realizada en Bogotá en 1953 y luego en Cali en 1955 donde se realizó la Segunda Convención de la especialidad habiéndose desatado una controversia ante la incredulidad de algunos colegas de Medellín quienes se resistían a reconocer la existencia del Ca In-Situ del Cérvix; estas eran las primeras presentaciones en el país sobre esta patología. En este segundo evento el doctor Jordán en compañía del doctor Enrique Darnald presentó el primer trabajo colombiano que revisaba las experiencias en cirugía radical con la técnica de Werthein en estados iniciales de carcinoma infiltrante del cuello uterino. Durante la jefatura del profesor Jordán se inauguró la Sección de Seguimiento con la cual se trató de dar solución a la alta tasa de abandono por parte de las pacientes, y al frente de esa sección en ginecología ha estado la Trabajadora Social Luz Myriam Palomino: también se dio impulso a la Liga de Lucha Contra el Cáncer, la cual a pesar de haber sido fundada en 1947, sólo a partir de 1960 tomó el sitio que le correspondía en los programas de prevención y diagnóstico precoz como auxiliar del Instituto en esta materia gracias al respaldo dado por el doctor Jordán y por el director el doctor Mario Gaitán Yanguas. Desde 1962 el Instituto cuenta con un Voluntariado excelente y en Ginecología Marina de Luna fue entre otras una digna representante.

La quimioterapia cuya paternidad se atribuye a Paul Erlich quien hacia 1898 había descubierto el primer agente alquilante que fue utilizado cincuenta años más tarde, ingresó al país en agosto de 1947 con la visita del profesor Salvatore P Lucía de San Francisco cuando se aplicó mostaza nitrogenada en linfoblastomas. Sin embargo, sólo a comienzos de la década de los sesenta se inició la aplicación de alquilantes en el manejo complementario de patología ovárica maligna y a finales de los años setenta se implementó la poliquimioterapia.

La microcolpohisteroscopia que había sido introducida por Hamou en París a finales de los años setenta fue realizada por primera vez en Colombia para descartar o confirmar patología maligna endocervical y/o endometrial en 1981 en el INC.

La cirugía laparoscópica implementada en el Instituto a mediados de la década de los sesenta tomó auge en ginecología a partir de 1979 especialmente en el diagnóstico y seguimiento de la patología ovárica y en el último año ha despertado interés su utilización en cirugía radical.

En 1980 la "Escuelita del Dr. Jordán”, como jocosamente llamaban al grupo algunos colegas, pasó a ser dirigida por el doctor Hugo Quijano Morales, egresado de la Universidad Nacional y quien se había vinculado al servicio en 1960, había realizado Fellows en oncología ginecológica entre otros en el Massachusetts General Hospital. El doctor Quijano colaboró decididamente en la implementación del Plan Nacional de Detección Precoz y Control de Cáncer de Cuello Uterino del cual fue gestor el doctor Juan Manuel Zea Gutiérrez en 1989, programa con el cual se busca dar solución definitiva a mediano plazo a uno de los problemas más graves que en materia de salud pública tiene el país como quiera que esta patología es la primera causa de morbilidad por cáncer en las mujeres y ocupa el segundo lugar en mortalidad por cáncer después del ca gástrico en el sexo femenino. El doctor Quijano dio impulso a la docencia y al entrenamiento para médicos especialistas en el programa de Oncología Ginecológica, fomentó las reuniones multidisciplinarias, realizó varios estudios de investigación y fue conferencista invitado en varios eventos de la especialidad; además ocupó la Jefatura de Cirugía, la de Atención Médica y fue Director Encargado del Instituto. En diciembre de 1992 el profesor Quijano se retiró del Instituto para pasar a dirigir el Departamento de Ginecología de la Fundación Santa Fe de Bogotá.

El Grupo de Ginecología del INC tiene una gran influencia a nivel nacional no sólo en materia académica y asistencial sino en políticas de salud pública al determinar directrices en la materia. Permanentemente se entrenan 5 ó 6 especialistas en Oncología Ginecológica con programas de 2 años, rotan 5 ó 6 residentes de último año de las diferentes escuelas de medicina del país, se dictan cursos de Patología Cervical y Colposcopia para ginecólogos de diferentes regiones colombianas y del exterior y se da docencia a estudiantes de medicina, enfermería y carreras afines de varias universidades de la capital.

Una de las más importantes innovaciones dentro del Grupo ha sido la implementación de talleres informativos para las pacientes las cuales se realizan con participación muy activa de las enfermas y sus familiares, de los diferentes especialistas que participan en el tratamiento encabezados por el ginecólogo y con asesoría de psiquiatras y sicólogos, actividades que han permitido disminuir el nivel de angustia de las pacientes y de sus familiares y obtener una actitud más positiva ante la enfermedad y el tratamiento.

Como una gratificación a todas estas actividades el trabajo "Cáncer de Cuello Uterino" presentado por el grupo en el último Congreso Nacional de Obstetricia y Ginecología en marzo de 1994, fue galardonado con el Premio Nacional de Ginecología al ocupar el primer lugar, honor que recibimos como un homenaje a todos aquellos que nos han formado o que nos han precedido como los doctores Hernán Posada, Enrique Leaño, Danilo Torres, Nelsy Prada de Acevedo, Hernando Rodríguez y 
Alfredo Támara, fuera de los maestros antes mencionados.

Hay actualmente en el país alrededor de 50 ginecólogos oncólogos en su mayoría egresados del Instituto, número que por su calidad y actividad ha permitido constituir la ASOCIACION COLOMBIANA DE GINECOLOGOS ONCOLOGOS la cual en conjunto con el Grupo de Ginecología del Instituto y la Revista Colombiana de Obstetricia y Ginecología elaboraron y publicaron el MANUAL DE NORMAS DE MANEJO DEL CANCER
GINECOLOGICO en marzo de 1993, el cual tuvo una acogida extraordinaria y pretende unificar criterios a nivel nacional para poder realizar estudios multicéntricos en el país, para facilitar entre otras cosas el registro de cáncer y una adecuada orientación en materia de prevención. Por el alto número de pacientes atendidos, por la trayectoria, por la calidad de atención que se brinda y por los logros obtenidos, el Servicio de Ginecología del Instituto Nacional de Cancerología es único en el país y pionero en su género en el conçierto latinoamericano.

\section{EVENTOS}

LA SOCIEDAD COLOMBIANA DE OBSTETRICIA Y GINECOLOGIA, LA ASOCIACION COLOMBIA. NA DE ANGIOLOGIA Y CIRUGIA VASCULAR, LA ASOCIACION COLOMBIANA DE HEMATOLOGIA, Y LA SOCIEDAD COLOMBIANA DE ORTOPEDIA Y TRAUMATOLOGIA invitan al Simposio sobre "TROMBOSIS VENOSA". Sede Club Médico de Bogotá septiembre 8 de 1994 de las 19:00 a las 21:00 horas, con COCTEL al finalizar.

Entrada Libre con inscripción previa al teléfono 2681485.

Puntaje académico para Miembros de la SCOG. 20 Puntos.

\section{CONGRESO COLOMBIANO DE FERTIIIDAD Y ESTERILIDAD}

Barranquilla Septiembre 8 - 12/94, informes Calle 79 No. $52-55$ Tel: 564383 Fax: 563657 Barranquilla

\section{UNIVERSIDAD DE ANTIOQUIA FACULTAD DE MEDICINA INVITAN TOPICOS SELECTOS DE} INFECTOLOGIA 1994

16 y 17 de septiembre de 1994 Teatro Pablo Tobón Uribe - Medellín

Informes: Depto. de Microbiología y Parasitología Tel.: (942) 635411 Medellín

\section{FIGO 94}

XIV CONGRESO MUNDIAL DE GINECOLOGIA Y OBSTETRICIA

Septiembre 24 al 30 de 1994 , Montreal - Canadá

Informes: Tel.: 2699903

\section{SIMPOSIO DE ACTUALIZACION EN CLIMATERIO}

Hotel Bogotá Plaza, del 27 al 28 de octubre de 1994.

Informes: Tel: 2681485. Puntaje Académico para Miembros SCOG 20 puntos.

\section{CONGRESO ECUATORIANO DE OBSTETRICIA Y GINECOLOGIA. VIII JORNADAS} BOLIVARIANAS

Noviembre 7 al 11 de 1994 en Quito . Ecuador.

Informes Secretaría. Polonia 101 y Eloy Alfaro. Teléfonos: 506667 - 221195-22289 Fax: 221-799 Quito, Ecuador.

LA SOCIEDAD IBEROAMERICANA DE ENDOSCOPIA GINECOLOGICA (SIAEG), invita aI IV CONGRESO INTERNACIONAL, "IMAGENOLOGIA Y REPRODUCCION SIGLO XXI", en Cancún México del 15 - 18 de marzo de 1995.

Informes: Tel.: (525) 203-86-20, 531-29-45, 545-08-98 Fax: (525) 254-7565. 